\title{
ARTICLE
}

Epidemiology

\section{Impact of neuroendocrine morphology on cancer outcomes and stage at diagnosis: a UK nationwide cohort study $2013-2015$}

Tracey S. E. Genus ${ }^{1,2}$, Catherine Bouvier ${ }^{1}$, Kwok F. Wong ${ }^{2}$, Rajaventhan Srirajaskanthan ${ }^{3,4}$, Brian A. Rous ${ }^{5}$, Denis C. Talbot ${ }^{6}$, Juan W. Valle ${ }^{7}{ }^{7}$, Mohid Khan $^{8}$, Neil Pearce ${ }^{9}$, Mona Elshafie ${ }^{10}$, Nicholas S. Reed ${ }^{11}$, Eileen Morgan ${ }^{12}$, Andrew Deas ${ }^{13}$, Ceri White ${ }^{14}$, Dyfed Huws ${ }^{14}$ and John Ramage ${ }^{3,4}$

BACKGROUND: The diagnosis of neuroendocrine neoplasms (NENs) is often delayed. This first UK population-based epidemiological study of NENs compares outcomes with non-NENs to identify any inequalities.

METHODS: Age-standardised incidence rate (ASR), 1-year overall survival, hazard ratios and standardised mortality rates (SMRs) were calculated for all malignant NENs diagnosed 2013-2015 from UK national Public Health records. Comparison with non-NENs assessed 1-year overall survival (1YS) and association between diagnosis at stage IV and morphology.

RESULTS: A total of 15,222 NENs were identified, with an ASR (2013-2015 combined) of 8.6 per 100,000 (95\% Cl 8.5-8.7); 4.6 per 100000 (95\% Cl, 4.5-4.7) for gastro-entero-pancreatic (GEP) NENs. The 1 YS was $75 \%$ (95\% Cl, 73.9-75.4) varying significantly by sex. Site and morphology were prognostic. NENs (predominantly small cell carcinomas) in the oesophagus, bladder, prostate, and female reproductive organs had a poorer outcome and were three times more likely to be diagnosed at stage IV than non-NENs. CONCLUSION: Advanced stage at diagnosis with significantly poorer outcomes of some NENs compared with non-NENs at the same anatomical site, highlight the need for improved access to specialist services and targeted service improvement.

British Journal of Cancer (2019) 121:966-972; https://doi.org/10.1038/s41416-019-0606-3

\section{BACKGROUND}

Neuroendocrine neoplasms (NENs) occur throughout the body, the most common sites including pulmonary, digestive and skin. NENs range from well-differentiated neuroendocrine tumours (NETs) to poorly differentiated carcinomas (NECs, small- and largecell type) (World Health Organisation [WHO] Classification 2017) having varying potential, low grade and indolent to high grade and aggressive. The heterogeneous clinical presentation and biology of NENs cause significant challenges in diagnosis and management, ${ }^{1}$ with NENs often misdiagnosed, or diagnosis frequently delayed. ${ }^{2}$

The UK cancer registries in England, Scotland, Wales and Northern Ireland systematically collect high quality histologically confirmed and validated data on all malignant cancers diagnosed. However, previous coding systems have made comprehensive isolation of NEN data for epidemiological studies impossible. Registration in the ICD-O-3 (combined topology and morphology) coding system for cases diagnosed from 2013 onward, ${ }^{3}$ and TNM staging of GEP-NENs from $2010^{4}$ have now allowed the first descriptive epidemiological study of NENs diagnosed in the UK, and the first analysis by TNM stage.

The aim of this study was to determine the epidemiology of NENs diagnosed in the UK, and to ascertain whether there are any disparities in outcomes between NENs and non-NENs at the same anatomical site.

\section{METHODS}

Study population

A comprehensive population-based cohort study was undertaken for all persons diagnosed with NENs in the UK between 1 January 2013 and 31 December 2015 with follow-up to the week commencing 12 January 2017, using patient-level data collected by Public Health England National Cancer Registration and Analysis Service (PHE NCRAS), and pseudo-anonymised data from NHS National Services Scotland, Public Health Wales Welsh Cancer

\footnotetext{
${ }^{1}$ Neuroendocrine Tumour Patients Foundation, Leamington Spa, UK; ${ }^{2}$ National Cancer Registration and Analysis Service, Public Health England, Birmingham, UK; ${ }^{3}$ Department of

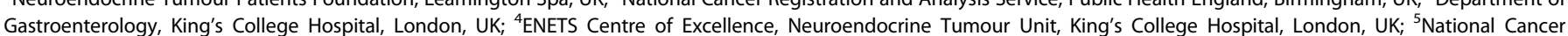

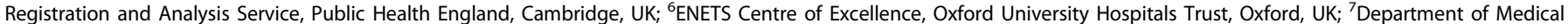

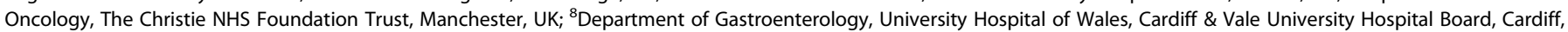

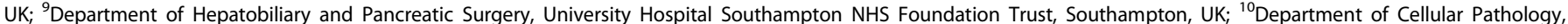

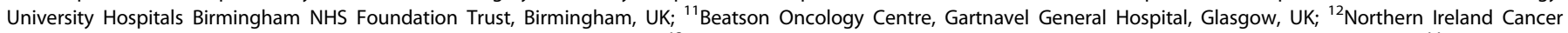

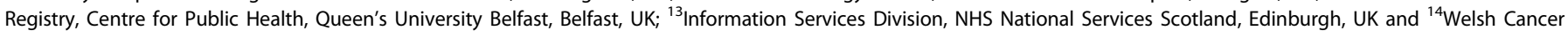
Intelligence \& Surveillance Unit, Public Health Wales, Cardiff, UK
} Correspondence: Tracey S. E. Genus (tracey.genus@phe.gov.uk)

Received: 22 January 2019 Revised: 21 September 2019 Accepted: 1 October 2019 Published online: 25 October 2019 
Intelligence \& Surveillance Unit and Public Health Agency Queen's University Belfast. These registries had coverage of a 2015 midyear total population of $65,110,000$. Socioeconomic status (not available for Scotland) was measured by deprivation quintiles based on: area deprivation for England and N. Ireland, produced by the Ministry of Housing, Communities and Local Government (formerly the Department for Communities and Local Government); and aspects of deprivation experienced in income for Wales, produced by the Welsh Government using the Welsh Index of Multiple Deprivation. English data for non-NENs was also available for comparison.

\section{Tumour classification}

NENs were defined by the WHO 2015 classification excluding diffuse pulmonary neuroendocrine hyperplasia. Tumours occurring at all anatomical sites between $\mathrm{C} 00$ and $\mathrm{C} 80$ according to the 10th edition of the WHO International Classification of Disease (ICD-10) codes were included, and morphology codes included 8013 (excluding lung [C34 and C78]), 8041-8045 (excluding lung), 8150-8158, 8240-8247, 8249 and 9091 according to the WHO International Classification of Diseases for Oncology, 3rd Edition (ICD-O-3). All were behaviour code 3 (malignant), 6 (metastatic) or 9 (malignant, uncertain whether primary or metastatic).

Tumours were staged according to the American Joint Committee on Cancer (AJCC) TNM staging for $\mathrm{NENs}^{5}$ and the European Neuroendocrine Tumor Society (ENETS) recommendations for the staging of GEP-NENs ${ }^{6}$ and graded using the ENETS grading system (WHO 2010) for GEP-NENs, ${ }^{7-9}$ or according to pathological grading of differentiation for other sites. Ki-67 status was not uniformly captured and is not recognised yet in many organ systems. Due to this being a registry study, we were unable to revisit each tissue specimen to acquire it, most grades were therefore based on a morphology of "poorly differentiated" or "well-differentiated" so grade 1 and grade 2 were combined to reduce inaccuracies. Tumour grades were classified: grade 1 and grade 2 combined-NET G1/G2 (functioning tumours including insulinomas, glucagonomas etc. with morphology codes 8150-8153, 8155-8158 and tumours with morphology codes 8240-8242, 8249, and 9091); grade 3-NEC G3 (large cell carcinoma, small cell carcinoma, combined small cell carcinoma, neuroendocrine carcinoma NOS with morphology codes 8013, 8041-8045, and 8246); Mixed Adeno-Neuroendocrine Carcinoma (MANEC) (Now known as 'goblet cell adenocarcinomas') goblet cell carcinoid, mixed adenoneuroendocrine carcinoma, tubular adenocarcinoid tumour with morphology codes 8243-8245); and "other" (pancreatic endocrine tumour malignant, mixed pancreatic endocrine and exocrine tumour malignant, and Merkel cell carcinoma morphology codes 8150, 8154 and 8247, respectively).

\section{Statistical analysis}

All analyses were performed using STATA/MP 15.1 for Windows software program. ASRs for the UK 2013-2015 combined, UK 2013-2015 annual and 2001-2015 time series (England only) were calculated using ICD-O-2 codes for diagnoses between 2001 and 2012 (morphology codes 8013 [large cell neuroendocrine carcinoma], and 8249 [atypical carcinoid tumour] were not available), 1971-2015 mid-year population estimates Office of National Statistics (ONS) data, ${ }^{10}$ and the 2013 European standard population. Of the cohort, 15,106 persons were included in survival and mortality analyses, excluding those with a death certificate only registration and including the first tumour in those with multiple tumours, or the tumour with known stage if multiple tumours had the same diagnosis date. 1-year overall survival (1YS) estimates (also for non-NENs) were made using the Kaplan-Meier method with log rank tests. Multivariable survival analysis using Cox (proportional hazards) regression and likelihood ratios were performed with the model adjusting for clinically relevant independent variables sex, age, stage, site, morphology, grade, deprivation and year of diagnosis (all assessed for significant association with overall survival at $p<0.05$ ). Standardised mortality rates, for those diagnosed between 1 January 2013 and 31 December 2015, for all-cause mortality over the disease duration, adjusting for explanatory variables age, sex and calendar period, were calculated by means of the life-table approach using ONS death registrations, including persons aged $0-100$ years. ${ }^{11,12}$ Multiple logistic regression estimated the odds ratios (OR) and $95 \%$ confidence intervals $(\mathrm{Cl})$ for association of diagnosis at stage IV with morphology (NEN or non-NEN), for all people diagnosed with cancer between 2013 and 2015 in England, adjusting for sex and age. Vital status on 1 January 2017 was acquired from ONS.

\section{RESULTS}

Patients

Overall, 15,145 persons were diagnosed with 15,222 NENs between 2013 and 2015, of which 7,640 (50.4\%) were female. The average age at diagnosis was 65-69 years old with variation between sites (Table 1). The median follow-up time was 19.6 months (range $0-49.2$ months) and $24.8 \%(3,766)$ died within one year of diagnosis.

\section{Tumours}

The most common primary tumour sites were pulmonary $20 \%$, small intestine $13 \%$, appendix $12 \%$, pancreas $9 \%$, skin $7 \%$, colon and caecum $5 \%$, stomach $5 \%$, rectum $4 \%$, bladder $3 \%$ and oesophagus $3 \%$. Stage distribution was $37 \%$ localised (18\% stage I, $9 \%$ stage II and $11 \%$ stage III), $23 \%$ metastasised (stage IV) and $39 \%$ unknown. Around $42 \%$ of the neoplasms were NETs, $28 \%$ neuroendocrine carcinomas and $9 \%$ small cell carcinomas. Nearly half of the tumours (48\%) were low grade (grade 1 or 2 ) and over a third (35\%) high grade (grade 3 ), the remaining tumours were MANEC (3.5\%) and other (13\%). Tumour breakdown by proportion of stage IV, grade 3 and by morphology for the most common sites is shown in Table 1.

\section{Incidence}

The UK ASR was 8.6 per 100,000 (2013-2015 combined), 8.1 in females and 9.1 in males; 4.6 for GEP-NENs overall, the second most common gastrointestinal tumour. ${ }^{13}$ Incidence by other sites are listed in Table 2.

The 2015 UK annual incidence was 8.7 per 100,000 $(8.2$ [95\% Cl, 7.8-8.5] in females and 9.2 in males [95\% Cl, 8.8-9.6]). It increased steadily, from 3.9 cases per 100,000 in 2001 to 7.9 per 100,000 in 2012 in England, at around 0.4 cases per 100,000 per year (Fig. 1 and Table 2), although it must be noted that these figures are from ICD-O-2 coded data so do not include morphology codes 8013 and 8249.

\section{Survival}

The overall 1YS probability for persons diagnosed with NENs was $74 \%$ (Table 2), significantly higher in females $78 \%$ than in males $71 \%$ ( $p<0.001$ for comparison between sexes). There was a small but significant difference between the least deprived $77 \%$ and most deprived $73 \%$. As expected, small cell neuroendocrine carcinoma had the poorest survival probability of all morphologies, $41.4 \%$, whilst NETs had the highest at $>90 \%$ (inclusive of all sites).

The median survival for oesophageal, prostate and bladder NENs were 5.7 (4.5-7.5), 7.8 (5.8-9.1) and 11.3 (9.9-12.8) months, respectively. Survival for the other sites exceeded $50 \%$ at the longest time period so median survival could not be calculated for these.

The 1YS probability for people diagnosed with pulmonary, pancreatic, stomach and small intestine NENs, predominantly well differentiated NETs, was much higher than for non-NENs at these sites. Conversely, the 1YS probability for people diagnosed with 
Impact of neuroendocrine morphology on cancer outcomes and stage at...

TS.E. Genus et al.

Table 1. Demographic and clinical characteristics table

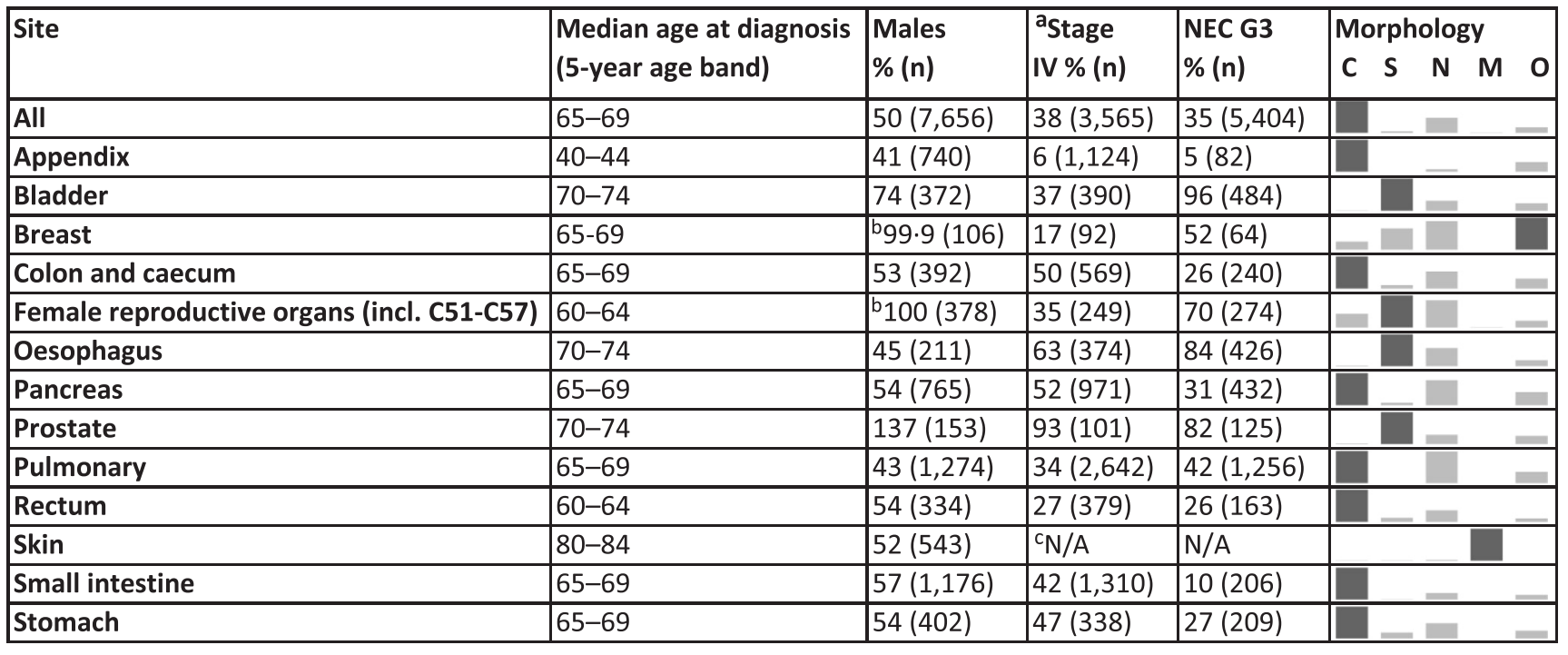

Morphology sparklines: represents the distribution of morphologies by site, the darkest column the most frequent morphology

$C$ neuroendocrine (carcinoid) tumour, $S$ small cell neuroendocrine carcinoma, $N$ neuroendocrine carcinoma, $M$ merkel cell carcinoma, $O$ other, $N E C$ G3 neuroendocrine carcinoma grade $3, n$ number of patients, N/A not applicable

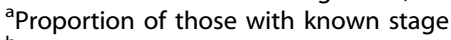

${ }^{\mathrm{b}}$ Females

cNon-melanoma skin cancers are not currently staged

oesophageal, prostate, bladder and to a lesser extent female reproductive organ, colon, and breast NENs, predominantly NECs, was much lower than for non-NENs at these sites (Table 3) and these tumours were at least three times more likely to be diagnosed at stage IV. Around $42 \%$ of oesophageal NENs were stage IV and grade 3 tumour pathology with a 1YS probability of $22 \%$ (95\% Cl 16.7-28.5); the predominant morphology at this site was small cell neuroendocrine carcinoma (Table 1). Likewise, $75 \%$ of bladder and $74 \%$ of prostate NENs were small cell carcinomas or combined small cell carcinomas.

Survival decreased more with increasing stage $(p<0.001$ for comparison between all stages) and grade ( $p<0.001$, for comparison between all grades) combined, identifying the combination as potentially a better prognostic indicator than each variable independently (Supplementary Table 2). This was particularly noticeable for grade 1 and 2 combined vs grade 3 survival probabilities in those with stage IV: lung NENs, $65.1 \%$ (56.2-72.6) vs $26.2 \%$ (22.5-30), colon NENs, $81.7 \%(73.1-87.8)$ vs $21.6 \%(14.7-29.5)$; and pancreatic NENs $86.8 \%(81.4-90.8)$ vs $41.1 \%(34.6-47.4)$

Univariable Cox regression analysis determined that the hazard of death increased by 4\% (HR $1.0495 \% \mathrm{Cl}$ [1.03-1.06]) for each increase in deprivation of 1 quintile; $21 \%$ (HR $1.2195 \% \mathrm{Cl}$ [1.19-1.22]) for every 5 year increase in age; and 35\% (HR 1.35 95\% $\mathrm{Cl}$ [1.32-1.38]) with each one increment increase in stage at diagnosis. Risk decreased by 5\% (HR 0.95 95\% Cl [0.92-0.98]) for each year of diagnosis between 2013 and 2015.

Multivariable Cox analysis adjusting for predictor variables sex, age, stage, site, morphology, grade, deprivation and year of diagnosis on mortality (Table 2) determined the hazard of death was up to $18 \%$ lower for women than men; those aged over 75 years three times that of those aged under 54 years; and those with stage IV NENs more than twice that of those with stage III NENs. Some sites were associated with increased hazard, the hazard in those with gallbladder, anal and oesophageal NENs was similar to that of those with secondary tumours (HR $3.295 \% \mathrm{Cl}$ [2.5-4.1]) (Supplementary Table 1). Those who lived in the most deprived areas had up to a $41 \%$ increase in hazard of death when compared with the least deprived.

\section{Mortality}

SMRs were used to measure survival relative to the general population (Table 2). Deaths occurred nearly four times more frequently in those diagnosed with NENs; varying from nearly three times more in those aged over 75 years to 10 times more in those aged 55-64 years at diagnosis, and with the same frequency as those in the general public for those with stage I to 10 times more in those with stage IV cancer.

\section{DISCUSSION}

Incidence

The incidence of NENs appears to be rising in this and other international studies. ${ }^{14,15}$ This rise may be real, or may be an artefact of the use of diagnostic imaging ${ }^{15}$ with improved sensitivity, and increased clinical vigilance resulting in incidental detection of asymptomatic lesions. ${ }^{14}$ Also, in this study the upward trend in incidence between 2013, the beginning of ICD-O3 coding in the UK and 2015 is less pronounced than that seen previously. We need future studies using a wider timeframe to determine whether the incidence of NENs is still rising or beginning to plateau.

In the UK, the incidence of NENs in the rectum ranked after lung, small intestine, appendix, pancreas, stomach and colon and caecum combined, in comparison with the most recent international study, in the USA, ${ }^{15}$ where rectum was the 3rd most common after lung and small intestine, with appendix last. In the USA, colorectal screening starts at 50 years old ${ }^{16}$ compared with 55 years in the UK and could be improving detection; appendiceal NETs only became reportable in the USA from January 2015 (SEER 


\begin{tabular}{|c|c|c|c|c|c|c|c|}
\hline \multirow[t]{2}{*}{ Variables } & & \multirow[t]{2}{*}{ Tumour count } & \multirow{2}{*}{$\begin{array}{l}\text { Incidence } \\
\text { Age-standardised rate } \\
\text { (ASR) (CI) (per 100,000 } \\
\text { persons) }\end{array}$} & \multicolumn{2}{|l|}{ Survival $^{\mathrm{a}}$} & \multicolumn{2}{|l|}{ Mortality $^{\mathrm{a}}$} \\
\hline & & & & $\begin{array}{l}\text { 1-year overall survival } \\
\text { (Kaplan--Meier) (Cl) }\end{array}$ & $\begin{array}{l}\text { Cox proportional } \\
\text { hazards regression } \\
\text { multi-variable }(\mathrm{Cl})\end{array}$ & $\begin{array}{l}\text { Observed/ } \\
\text { expected deaths }\end{array}$ & $\begin{array}{l}\text { Standardised } \\
\text { mortality ratio } \\
\text { (SMR) (CI) }\end{array}$ \\
\hline All & & 15,222 & $8.6(8.46-8.74)$ & 74.7 (73.9-75.4) & - & $5233 / 1442.6$ & $3.6(3.5-3.7)$ \\
\hline \multirow[t]{2}{*}{ Sex } & 1 & 7538 & $9.14(8.93-9.35)$ & $71.3(70.3-72.4)$ & 1 (reference) & 2884/821.5 & $3.5(3.4-3.6)$ \\
\hline & 2 & 7684 & $8.06(7.88-8.24)$ & 77.9 (76.9-78.8) & $0.9(0.8-0.9)$ & $2349 / 621.1$ & $3.8(3.6-3.9)$ \\
\hline \multirow[t]{4}{*}{ Age } & $0-54$ & 3668 & $1.88(1.82-1.94)$ & $90.2(89.2-91.2)$ & $0.5(0.5-0.6)$ & $545 / 156.6$ & $3.5(3.2-3.8)$ \\
\hline & $55-64$ & 2865 & $1.62(1.56-1.68)$ & $78.7(77.2-80.2)$ & $0.8(0.7-0.8)$ & $553 / 56.6$ & $9.8(9-10.6)$ \\
\hline & $65-74$ & 4302 & $2.47(2.39-2.54)$ & $72.5(71.1-73.9)$ & 1 (reference) & $1284 / 223.8$ & $5.7(5.4-6.1)$ \\
\hline & $75+$ & 4387 & $2.62(2.54-2.7)$ & $60.5(58.9-61.9)$ & $1.5(1.4-1.6)$ & $2851 / 1005.7$ & $2.8(2.7-2.9)$ \\
\hline \multirow[t]{5}{*}{ Deprivation } & 1- least deprived & 2861 & $1.65(1.59-1.71)$ & 77.3 (75.7-78.8) & 1 (reference) & $920 / 317.3$ & $2.9(2.7-3.1)$ \\
\hline & 2 & 2915 & $1.67(1.61-1.73)$ & 75.3 (73.7-76.8) & $1.1(1-1.2)$ & $990 / 303.6$ & $3.3(3.1-3.5)$ \\
\hline & 3 & 2835 & $1.62(1.56-1.68)$ & 75.9 (74.3-77.5) & $1.1(1-1.2)$ & $978 / 278.4$ & $3.5(3.3-3.7)$ \\
\hline & 4 & 2640 & $1.51(1.45-1.57)$ & 73.1 (71.3-74.7) & $1.2(1.1-1.3)$ & $946 / 240.1$ & $3.9(3.7-4.2)$ \\
\hline & 5- most deprived & 2465 & $1.39(1.34-1.45)$ & $73.3(71.5-75.1)$ & $1.3(1.2-1.4)$ & $855 / 184.6$ & $4.6(4.3-5)$ \\
\hline \multirow[t]{3}{*}{ Diagnosis Year } & 2013 & 4895 & $8.41(8.18-8.66)$ & $74.1(72.8-75.3)$ & 1 (reference) & $1997 / 622.7$ & $3.2(3.1-3.4)$ \\
\hline & 2014 & 5126 & $8.67(8.43-8.92)$ & $74.4(73.2-75.6)$ & $1(0.9-1.1)$ & $1799 / 487.5$ & $3.7(3.5-3.9)$ \\
\hline & 2015 & 5201 & $8.68(8.44-8.92)$ & $75.5(74.3-76.7)$ & $1.1(1-1.1)$ & $1437 / 332.5$ & $4.3(4.1-4.6)$ \\
\hline \multirow[t]{16}{*}{ Site } & Appendix & 1807 & $0.95(0.9-0.99)$ & $96.4(95.4-97.2)$ & 1 (reference) & $122 / 89.1$ & $1.4(1.1-1.6)$ \\
\hline & Breast & 107 & $0.06(0.05-0.07)$ & $84.8(76.3-90.4)$ & $1.5(1-2.3)$ & $25 / 13.4$ & $1.9(1.3-2.8)$ \\
\hline & Bladder & 500 & $0.31(0.28-0.34)$ & $51.2(46.6-55.7)$ & $2.4(1.9-3.1)$ & $323 / 59.9$ & $5.4(4.8-6)$ \\
\hline & Colon and caecum & 734 & $0.41(0.38-0.44)$ & $72(68.5-75.2)$ & $2.4(1.9-3.1)$ & $249 / 62.9$ & $4(3.5-4.5)$ \\
\hline & $\begin{array}{l}\text { Female reproductive } \\
\text { organs (incl.C51-C57) }\end{array}$ & 378 & $0.2(0.18-0.22)$ & $69.2(64.1-73.7)$ & $2.8(2.2-3.7)$ & $158 / 12.8$ & $12.3(10.6-14.4)$ \\
\hline & Oesophagus & 470 & $0.26(0.24-0.29)$ & $35.5(31-40.1)$ & $3.4(2.7-4.4)$ & $366 / 26.1$ & $14(12.7-15.5)$ \\
\hline & Pancreas & 1415 & $0.8(0.76-0.84)$ & $80.6(78.4-82.6)$ & $2(1.6-2.5)$ & $421 / 112.9$ & $3.7(3.4-4.1)$ \\
\hline & Prostate & 137 & $0.08(0.07-0.10)$ & $31.5(23.6-39.8)$ & $2.6(1.9-3.5)$ & $114 / 8.6$ & $13.2(11-15.9)$ \\
\hline & Pulmonary & 2989 & $1.68(1.62-1.74)$ & $73.7(72-75.3)$ & $2.9(2.3-3.6)$ & $1019 / 232$ & $4.4(4.1-4.7)$ \\
\hline & Rectum & 622 & $0.32(0.29-0.35)$ & 81 (77.6-83.9) & $2.7(2-3.5)$ & $151 / 42.6$ & $3.5(3-4.2)$ \\
\hline & Skin & 1044 & $0.62(0.58-0.66)$ & $74.3(71.5-76.9)$ & $2.1(1.5-3)$ & $460 / 292.2$ & $1.6(1.4-1.7)$ \\
\hline & Small Intestine ${ }^{b}$ & 2054 & $1.17(1.12-1.23)$ & $89.6(88.1-90.8)$ & $1.3(1-1.7)$ & $157 / 83.7$ & $1.9(1.6-2.2)$ \\
\hline & lleum & 1,024 & $0.53(0.5-0.57)$ & $92.8(91-94.2)$ & ND & $149 / 120.4$ & $1.2(1.0-1.4)$ \\
\hline & Duodenum & 316 & $0.18(0.16-0.2)$ & $87.3(83-90.6)$ & ND & $54 / 34.8$ & $1.5(1.2-2.0)$ \\
\hline & Jejunum & 40 & $0.02(0.02-0.03)$ & 89.4 (74.1-95.9) & ND & $8 / 5.7$ & $1.4(0.7-2.8)$ \\
\hline & Stomach & 749 & $0.43(0.4-0.46)$ & $74.1(70.8-77.2)$ & $2.4(1.9-3.1)$ & $240 / 69.9$ & $3.4(3-3.9)$ \\
\hline \multirow[t]{5}{*}{ Stage } & 1 & 2691 & $1.48(1.42-1.53)$ & $96.1(95.3-96.8)$ & 1 (reference) & $208 / 234.4$ & $0.9(0.8-1)$ \\
\hline & ॥ & 1412 & $0.79(0.75-0.84)$ & $87.6(85.7-89.2)$ & $2.1(1.8-2.6)$ & $283 / 150.5$ & $1.9(1.7-2.1)$ \\
\hline & III & 1619 & $0.92(0.87-0.97)$ & $81.7(79.6-83.5)$ & $3.2(2.7-3.8)$ & $477 / 161.1$ & $3(2.7-3.2)$ \\
\hline & IV & 3493 & $2.01(1.94-2.08)$ & $48.8(47-50.5)$ & $8.2(7.1-9.5)$ & $2141 / 217.1$ & $9.9(9.5-10.3)$ \\
\hline & Unknown & 6007 & $3.39(3.3-3.48)$ & $74.5(73.3-75.6)$ & $3.6(3.1-4.2)$ & $2124 / 679.6$ & $3.1(3-3.3)$ \\
\hline \multirow[t]{4}{*}{ Grade } & MANEC ${ }^{c}$ & 537 & $0.3(0.27-0.33)$ & $84.3(80.8-87.2)$ & $0.5(0.1-3.6)$ & $136 / 42.3$ & $3.2(2.7-3.8)$ \\
\hline & NEC G3 & 5413 & $3.11(3.03-3.2)$ & $51.2(49.8-52.6)$ & $0.9(0.8-1)$ & $3225 / 409.3$ & $7.9(7.6-8.2)$ \\
\hline & NET G1/G2 & 7316 & $4.04(3.95-4.14)$ & $92.7(92.1-93.3)$ & $0.4(0.2-1.1)$ & $940 / 648.1$ & $1.5(1.4-1.5)$ \\
\hline & Other $^{d}$ & 1956 & $1.14(1.08-1.19)$ & $65.8(63.5-67.9)$ & 1 (reference) & $932 / 343$ & $2.7(2.5-2.9)$ \\
\hline \multirow[t]{10}{*}{ Morphology } & Atypical carcinoid tumour & 810 & $0.45(0.42-0.48)$ & $89.8(87.5-91.7)$ & $0.6(0.2-1.6)$ & $162 / 75.1$ & $2.2(1.8-2.5)$ \\
\hline & Neuroendocrine tumour & 6462 & $3.57(3.48-3.66)$ & $93.1(92.4-93.7)$ & $0.5(0.2-1.2)$ & $771 / 570.7$ & $1.4(1.3-1.5)$ \\
\hline & $\begin{array}{l}\text { Combined small cell } \\
\text { carcinoma }\end{array}$ & 285 & $0.17(0.15-0.19)$ & $54.8(48.5-60.6)$ & 1 (reference) & $175 / 26.2$ & $6.7(5.8-7.7)$ \\
\hline & Goblet cell carcinoid & 335 & $0.18(0.17-0.21)$ & $92.1(88.6-94.5)$ & $1.1(0.1-8.7)$ & $53 / 26.9$ & $2(1.5-2.6)$ \\
\hline & $\begin{array}{l}\text { Large cell neuroendocrine } \\
\text { carcinoma }\end{array}$ & 221 & $0.13(0.11-0.14)$ & $43.1(36.1-49.8)$ & $1.3(1.1-1.7)$ & $151 / 14.3$ & $10.6(9-12.4)$ \\
\hline & Merkel cell carcinoma & 1057 & $0.63(0.59-0.67)$ & $73.4(70.6-76)$ & $0.5(0.4-0.7)$ & $469 / 288.2$ & $1.6(1.5-1.8)$ \\
\hline & $\begin{array}{l}\text { Mixed adeno- } \\
\text { neuroendocrine } \\
\text { carcinoma }\end{array}$ & 188 & $0.11(0.09-0.12)$ & $68.6(61.2-74.9)$ & $1.6(0.2-12.6)$ & $82 / 14.8$ & $5.5(4.4-6.9)$ \\
\hline & $\begin{array}{l}\text { Neuroendocrine } \\
\text { carcinoma NOS }\end{array}$ & 4344 & $2.48(2.41-2.56)$ & $55.1(53.5-56.6)$ & $0.9(0.7-1)$ & $2362 / 326.9$ & $7.2(6.9-7.5)$ \\
\hline & Other ${ }^{\mathrm{e}}$ & 118 & $0.06(0.05-0.08)$ & $89.4(82.1-93.8)$ & $0.5(0.3-0.8)$ & $26 / 7.4$ & $3.5(2.4-5.1)$ \\
\hline & Small cell carcinoma & 1402 & $0.82(0.77-0.86)$ & $41.4(38.7-44.1)$ & $1.3(1.1-1.5)$ & $982 / 92$ & $10.7(10-11.4)$ \\
\hline \multicolumn{8}{|c|}{$\begin{array}{l}\text { Socioeconomic status was not available for Scotland, so deprivation for Scotland was not included see Methods } \\
\text { Only the most common sites are listed, for additional sites see Supplementary Table } 1 \\
\text { ND not determined } \\
\text { aExcluding "death certificate only" registration i.e. date of diagnosis = date of death } \\
\text { bSmall intestine includes: C17.0-duodenum; C17.1-jejunum; C17.2-ileum; C17.3-Meckel's diverticulum; C17.8; overlapping lesion of small intestine; } \\
\text { C17.9 small intestine, unspecified } \\
{ }^{c} \text { MANEC includes: goblet cell carcinoid; mixed adenoneuroendocrine carcinoma; tubular adenocarcinoid tumour } \\
{ }^{d} \text { Other grade includes pathology-graded: pancreatic endocrine tumour malignant; mixed pancreatic endocrine and exocrine tumour malignant; } \\
\text { neuroendocrine carcinoma NOS; small cell carcinoma NOS } \\
\text { eOther morphology includes: enterochromaffin carcinoid; gastrinoma malignant; glucagonoma malignant; insulinoma malignant; mixed pancreatic endocrine } \\
\text { and exocrine tumour malignant; pancreatic endocrine tumour malignant; somatostatinoma malignant; tubular carcinoid; and vipoma malignant }\end{array}$} \\
\hline
\end{tabular}




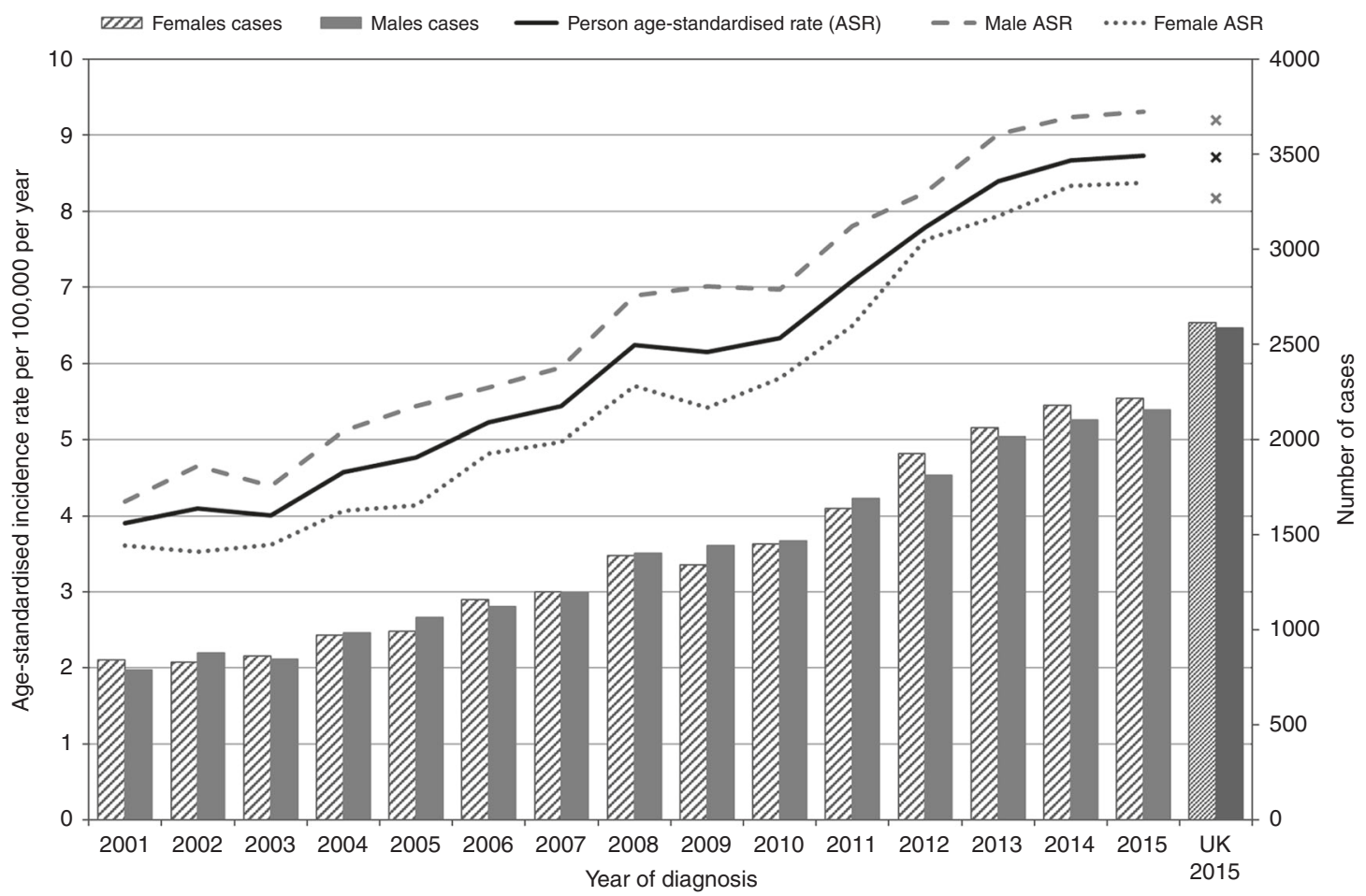

Fig. 1 Annual incidence (line graph) and count (bar chart) of NENs diagnosed in England 2001-2015 and the UK 2015 (cross markers)

\begin{tabular}{|c|c|c|c|c|c|c|c|c|}
\hline \multirow[t]{2}{*}{ Site } & \multicolumn{2}{|c|}{$\begin{array}{l}\text { Total number of } \\
\text { cases (stage I-IV) (n) }\end{array}$} & \multicolumn{2}{|c|}{ 1-year overall survival probability (\%) } & \multicolumn{4}{|c|}{$\begin{array}{l}\text { Association between NEN morphology and a diagnosis at } \\
\text { stage } 4\end{array}$} \\
\hline & NENs & Non-NENs & NENs $(95 \% \mathrm{Cl})$ & Non-NENs $(95 \% \mathrm{Cl})$ & $\begin{array}{l}\text { OR }(95 \% \mathrm{Cl}) \\
\text { (unadjusted) }\end{array}$ & $p$-value & $\begin{array}{l}\text { OR }(95 \% \mathrm{Cl}) \text { (age- } \\
\text { and sex-adjusted) }\end{array}$ & $p$-value \\
\hline Bladder & 362 & 19,859 & $52.4(47.4-57.1)$ & $74.9(74.4-75.5)$ & $3.2(2.6-4.0)$ & $<0.000$ & $3.2(2.6-4.1)$ & $<0.000$ \\
\hline Colon and caecum & 458 & 50,850 & $67.4(62.8-71.6)$ & $82.6(82.3-82.9)$ & $4(3.3-4.8)$ & $<0.000$ & $3.8(3.2-4.6)$ & $<0.000$ \\
\hline $\begin{array}{l}\text { Female } \\
\text { reproductive organs }\end{array}$ & 202 & 40,376 & $64.7(57.4-71.1)$ & $89.5(89.2-89.8)$ & $4.2(3.2-5.7)$ & $<0.000$ & $5.2(3.9-7)$ & $<0.000$ \\
\hline Oesophagus & 296 & 16,383 & $35.3(29.6-41)$ & $51.6(50.8-52.4)$ & $3.3(2.6-4.2)$ & $<0.000$ & $3.6(2.8-4.5)$ & $<0.000$ \\
\hline Pancreas & 838 & 8,936 & $77.6(74.5-80.3)$ & $31(29.7-31.5)$ & $0.6(0.5-0.7)$ & $<0.000$ & $0.5(0.5-0.7)$ & $<0.000$ \\
\hline Prostate & 52 & 98,963 & $21.1(11.3-33.0)$ & $95.5(95.4-95.6)$ & $41.7(16.6-104.9)$ & $<0.000$ & $45.1(17.8-113.9)$ & $<0.000$ \\
\hline Small Intestine & 1164 & 1157 & $91.2(89.4-92.7)$ & $61(58.4-63.1)$ & $0.9(0.8-1.1)$ & 0.314 & $0.9(0.8-1.1)$ & 0.326 \\
\hline Stomach & 278 & 10,938 & $63.4(57.3-68.9)$ & $48(47.4-49.1)$ & $1.0(0.8-1.3)$ & 0.24 & $0.9(0.8-1.2)$ & 0.881 \\
\hline
\end{tabular}

personal communication), explaining the comparatively lower incidence.

Survival and mortality

Multivariable analysis identified sex, age, site, stage, cell morphology and deprivation to be independently associated with mortality. Survival probabilities for NENs in the UK had similar trends to previous international studies with male sex, increasing age, stage, and grade and decreasing socioeconomic status associated with a poorer outcome. ${ }^{13,15}$ The much reduced 1 YS and mortality in metastatic tumours (stage IV) when compared with localised tumours (stage I-III) was particularly notable and in-line 
with a study of "all cancers" diagnosed in the UK, ${ }^{17}$ warranting further measures to ensure that the early diagnosis of NENs is a priority. People diagnosed with oesophageal, bladder, prostate, and female reproductive NENs had predominantly small cell carcinoma morphology, significantly poorer outcomes consistent with the results of previous smaller studies and case series, ${ }^{18-21}$ and were more likely to be diagnosed at stage IV. Some morphologies exhibited poorer survival probabilities than expected. This was the first large series study of MANEC reported and demonstrated a survival probability of $84 \%$ in comparison with the $95 \%$ previously reported. ${ }^{22}$ These findings highlight the need for the development of sub-specialist services to match the clinical need in the groups which have poorer outcomes.

\section{Limitations}

Tumours with uncertain behaviour (behaviour code 1) are not consistently captured by UK cancer registries because they have historically been deemed "benign" and were not included. This means that many small and indolent NETs of the stomach, rectum, appendix and pancreas may not have been included in historical data. There is an under representation of type 1 gastric NETs and stage I and II rectal NETs-that all have excellent 5- and 10-year survivals. This under representation may be significantly skewing the survival statistics presented in this study. Also, the high incidence of G3 NECs in this study, particularly those in the lung, are not representative of previous findings. In the lung, G3 NEC is used when there has been insufficient information to classify the tumour as either small cell carcinoma or large cell neuroendocrine carcinoma. Thus, the high incidence of G3 NEC in the lung is likely to represent small cell carcinoma, large cell neuroendocrine carcinomas and mixed tumours. This misclassification of G3 NECs could also be skewing the survival analysis. This is a caveat for ongoing classification recommendations for the purposes of analysis and audit. In the future, many of these tumours will be more consistently captured with improvements in WHO terminology.

The completeness of stage was only $61 \%$ for this cohort but is improving year on year. ICD-O-3 coding was implemented in $95 \%$ of the UK in 2013 (the exception Wales in 2016), prior to this morphology codes 8013 and 8249 were not available, many of these tumours coded carcinoma or adenocarcinoma NOS (not otherwise specified). Therefore, our incidence counts are underestimates, and survival analysis limited to only 1-year.

We calculated that the missing tumours from the Welsh cohort would equate to approximately 62 from common sites. Also, an audit of the English data using data collected by the NET Centre of Excellence at King's College Hospital found $14.6 \%$ of the tumours captured were not captured by NCRAS, many behaviour 1 . This would suggest the true incidence of NENs could be as high as 10 per 100,000 per year.

The capture of NENs irrespective of behaviour code, ICD-O-3 coding in Wales from 2016 and improvements in data completeness will resolve the afore mentioned issues in the future.

We were unable to calculate disease-specific survival and mortality due to death registrations by ICD-10 coding. However, recently it has become possible to link morphology to death registrations which will allow this in future studies.

\section{CONCLUSION}

This is the first population-based epidemiological study of NENs diagnosed in the UK, the results of which will be of value in future service planning. We determined that outcomes varied greatly between sites and morphologies. Comparison of NENs with nonNENs at the same site also found disparities. These differing outcomes between patient groups have a direct relationship with the healthcare resource required to manage them; and highlight the need for NENs to be seen at Centres of Excellence. Earlier diagnosis is necessary, and the identification of more diagnostic markers for NENs, particularly for extrapulmonary small cell carcinomas, required.

Future studies will allow 3- and 5-year survival estimates, and the availability of treatment data will allow more in-depth studies, and we are developing ways of collecting more detailed imaging, biochemistry, screening and symptom data which ultimately will be linked to the current cancer registry data. Pathologists have been instructed to include small benign pancreatic NETs as malignant as per WHO terminology and detail Ki67 on all specimen. Ki67 has not been routinely captured by the UK cancer registries to date, however this will change in mid-2020 with the implementation of version 9 of the Cancer Outcome and Services Data set (COSD), the national standard for reporting cancer in the NHS in England, in which Ki67 will be a required field and so captured by the English registry. Although the UK cancer registries do not currently hold complete data on MEN-1 diagnosis, the recent addition of genetic data means that this may also be available for future studies.

\section{ACKNOWLEDGEMENTS}

We would like to thank Sean McPhail, John Broggio, Jackie Charman, James Charnock, Sam Winters, Luke Hounsome and the PHE NCRAS team for all their help with data extraction and analysis. This work uses data provided by patients and collected by the NHS as part of their care and support.

\section{AUTHOR CONTRIBUTION}

T.G. did the literature search; study design; English data extraction; data collection; data analysis; data interpretation; wrote paper; created figures; and created tables. K. F.W. did data analysis and data interpretation. E.M. extracted Northern Irish data. A.D. extracted Scottish data. C.W. extracted Welsh data and edited paper. D.H. edited paper. C.B., R.S., B.A.R., D.C.T., J.W.V., M.K., N.P., M.E., N.S.R. and J.R. were the steering committee for the project; defined the cohort; did study design; data interpretation; and reviewed and edited the paper.

\section{ADDITIONAL INFORMATION}

Supplementary information is available for this paper at https://doi.org/10.1038/ s41416-019-0606-3.

Competing interests: The authors declare no competing interests.

Ethical approval and consent to participate: Data is collected by the UK cancer registries (PHE NCRAS, NHS National Services Scotland, Public Health Wales Welsh Cancer Intelligence \& Surveillance Unit and Public Health Agency Queen's University Belfast) under Regulations 2 and 5 of Section 251 of the NHS Act 2006. The Regulation provides the legal context to set aside the common-law duty of confidence to allow data to be collected without direct consent to support core public health functions. It is this permission that enables the UK cancer registries to collect detailed information from all people resident in the UK who have cancer or a reasonable suspicion of cancer.

Funding: This project was funded by the NET Patient Foundation.

Consent for publish: No individual's personal data was included, only aggregated data is presented.

Data availability: Supplementary datasets cited have been made available as supplementary material. Other data for this study is available on request from PHE NCRAS, NHS National Services Scotland, Public Health Wales Welsh Cancer Intelligence \& Surveillance Unit and Public Health Agency Queen's University Belfast

Note: This work is published under the standard license to publish agreement. After 12 months the work will become freely available and the license terms will switch to a Creative Commons Attribution 4.0 International (CC BY 4.0).

Publisher's note Springer Nature remains neutral with regard to jurisdictional claims in published maps and institutional affiliations. 


\section{REFERENCES}

1. Kunz, P. L., Reidy-Lagunes, D., Anthony, L. B., Bertino, E. M., Brendtro, K. Chan, J. A. et al. Consensus guidelines for the management and treatment of neuroendocrine tumors. Pancreas 42, 557-577 (2013).

2. Singh, S., Granberg, D., Wolin, E., Warner, R., Sissons, M., Kolarova, T. et al. Patientreported burden of a neuroendocrine tumor (NET) diagnosis: results from the first global survey of patients with NETs. J. Glob. Oncol. 3, 43-53 (2016).

3. Fritz A., Percy C., Jack A., Shanmugaratnam K., Sobin L., Max Parkin D. (eds.). International Classification of Diseases for Oncology, 3rd edn, first revision. (World Health Organization, Geneva, 2013).

4. Sobin L. H., Gospodarowicz M. K., Wittekind C. International Union Against Cancer TNM Classification of Malignant Tumors, 7th edn. (John Wiley \& Sons, Hoboken, 2011).

5. Edge S. E., Byrd D. R., Carducci M. A., Compton C. C., Fritz A. G., Greene F. L. et al. American Joint Committee on Cancer (AJCC) TNM staging for NETs. AJCC Cancer Staging Manual, 7th edn. (Springer, New York, 2010).

6. Kloppel, G., Couvelard, A., Perren, A., Komminoth, P., McNicol, A. M., Nilsson, O. et al. ENETS consensus guidelines for the standards of care in neuroendocrine tumors: towards a standardized approach to the diagnosis of gastroenteropancreatic neuroendocrine tumors and their prognostic stratification. Neuroendocrinology 90, 162-166 (2009).

7. Bosman F. T., Carneiro F., Hruban R. H., Theise, N. D. World Health Organisation classification of tumours of the digestive system. 4th edn. (IARC, Lyon, 2010)

8. Rindi, G., Kloppel, G., Alhman, H., Caplin, M., Couvelard, A., de Herder, W. W. et al. TNM staging of foregut (neuro)endocrine tumors: a consensus proposal including a grading system. Virchows Arch. 449, 395-401 (2006).

9. Rindi, G., Kloppel, G., Couvelard, A., Komminoth, P., Körner, M., Lopes, J. M. et al. TNM staging of midgut and hindgut (neuro) endocrine tumors: a consensus proposal including a grading system. Virchows Arch. 451, 757-762 (2007).

10. Office for National Statistics, (2016). Mid-2015 Population estimates for lower layer super output areas in England and Wales by single year of age and sex-supporting information (SAPE18DT1) annual small area population estimates. (Office for National Statistics (ONS), London, 2016).

11. Cronin, K. A. \& Feuer, E. J. Cumulative cause-specific mortality for cancer patients in the presence of other causes: a crude analogue of relative survival. Stat. Med 19, 1729-1740 (2000).

12. Office for National Statistics. National Records of Scotland, Northern Ireland Statistics and Research Agency. Death registrations by single year of age, United Kingdom, 1974-2017. pp. 2018. (ONS, London, 2018).

13. Yao, J. C., Hassan, M., Phan, A., Dagohoy, C., Leary, C., Mares, J. E. et al. One hundred years after "carcinoid": epidemiology of and prognostic factors for neuroendocrine tumors in 35,825 cases in the United States. J. Clin. Oncol. 26, 3063-3072 (2008).

14. Hallet, J., Law, C. H., Cukier, M., Saskin, R., Liu, N. \& Singh, S. Exploring the rising incidence of neuroendocrine tumors: a population-based analysis of epidemiology, metastatic presentation, and outcomes. Cancer 121, 589-597 (2015).

15. Dasari, A., Shen, C., Halperin, D., Zhao, B., Zhou, S., Xu, Y. et al. Trends in the Incidence, prevalence, and survival outcomes in patients with neuroendocrine tumors in the United States. JAMA Oncol. 3, 1335-1342 (2017).

16. Wolf, A. M. D., Fontham, E. T. H., Church, T. R., Flowers, C. R., Guerra, C. E., LaMonte, S. J. et al. Colorectal cancer screening for average-risk adults: 2018 guideline update from the American Cancer Society. CA Cancer J. Clin. 68 , 250-281 (2018)

17. Bannister, N., Broggio, J. (eds.). Cancer survival by stage at diagnosis for England (experimental statistics): adults diagnosed 2012, 2013 and 2014 and followed up to 2015. (Office for National Statistics, London, 2016).

18. Hudson, E., Powell, J., Mukherjee, S., Crosby, T. D., Brewster, A. E., Maughan, T. S. et al. Small cell oesophageal carcinoma: an institutional experience and review of the literature. Br. J. Cancer 96, 708-711 (2007).

19. Emmett, M. \& Gildea, C. Cervical cancer-does the morphological subtype affect survival rates? J. Obstet. Gynaecol. 38, 548-555 (2018).

20. Watson, G. A., Ahmed, Y., Picardo, S., Chew, S., Cobbe, S., Mahony, C. et al. Unusual sites of high-grade neuroendocrine carcinomas: a case series and review of the literature. Am. J. Case Rep. 19, 710-723 (2018).

21. Eltawil, K. M., Gustafsson, B. I., Kidd, M. \& Modlin, I. M. Neuroendocrine tumors of the gallbladder: an evaluation and reassessment of management strategy. J. Clin. Gastroenterol. 44, 687-695 (2010).

22. Brathwaite, S., Rock, J., Yearsley, M. M., Bekaii-Saab, T., Wei, L., Frankel, W. L. et al. Mixed adeno-neuroendocrine carcinoma: an aggressive clinical entity. Ann. Surg. Oncol. 23, 2281-2286 (2016). 